\title{
Khara-Khoto Documents Collected in Russia-First Exploration of Yuan Dynasty Hand-copied Book The Like Gods Prescription for Washing Hair and Treatment of Laucoma at Pathogenic Wind-toxic and Medical Prescription
}

\author{
Peng Liu \\ Northwest Normal University, Lanzhou Gansu, 730070, China
}

Keywords: Glaucoma, Knife-wound medicine, Diarrhea, Medical prescription of hand-copied book in Yuan Dynasty

\begin{abstract}
The date of the Like Gods Prescription for Washing Hair and Treatment of Laucoma may be the date of washing eyes in each month. And the compositions of medicinal materials may more involve material of saltpetre type and mulberry leaves. "Knife-step Medicine" in Medical Prescription may refer to "Knife-wound Medicine"; "Diarrhea Medicine" may have the double effect of treatment of "diarrhea" and "eye disease".
\end{abstract}

\section{Introduction}

Both the Like Gods Prescription for Washing Hair and Treatment of Laucoma at Pathogenic Wind-toxic and Medical Prescription are collected in Book Five of Khara-Khoto Documents Collected in Russia. Even the serial numbers are different, both were written in hand-copied book of Yuan Dynasty with some content lacking. So this article is to make textual criticisms and explanations on these two medical prescriptions.

\section{Textual criticisms and explanations on the Like Gods Prescription for Washing Hair and} Treatment of Laucoma at Pathogenic Wind-toxic

The hand-copied book the Like Gods Prescription for Washing Hair and Treatment of Laucoma at Pathogenic Wind-toxic written in Yuan Dynasty is a office-copy with a Russia Collected serial number of TK322(4), the back cover back up paper of Sixty Four divinatory symbols figure song with Russia collected serial number of TK322(1), collected in Page 81 of Book Five of Khara-Khoto Documents Collected in Russia. Recorded text is as followed:

1). The Like Gods Prescription for Washing Hair and Treatment of Laucoma at Pathogenic Wind-toxic

2). The eighth day, fourteenth day of the first lunar month; the seventh day, eighth day of lunar February; the sixth day, twelfth day of lunar March; the sixth day, eleventh day of April

3). The fifth day, twelfth day of May; the second day, twenty-fourth day of June; the seventh day, twenty-eighth day of July; fifteenth day and nineteenth day of August1

4).The third day, seventh day of September; twelfth day, thirteenth day of October 2 tenth day, eighteenth day 3 nineteenth day, seventh day

The prescription has medicinal material which has a name, no compositions. From the name of the prescription one can conclude that this medical prescription may have two kind of efficacy, one is washing hair, the other is treatment of glaucoma. The date prescription referred to may be the date of washing hair, plucking off hair or washing eyes.

Looking up the medical prescriptions in Chinese, it does with the medical prescriptions of the date of washing hair, plucking off and washing eyes in each month. It has been listed as below:

1 In the document right beside "fifteenth day" there written three characters "thirtieth day ".

2 According to the meaning of the text, the missing characters here should be "November".

3 According to the meaning of the text, the missing characters here should be "December". 


\section{The Gather of Medical Prescription Types recorded the "the date of plucking off hair in each month" as follows:}

One should pluck off white hair or moustache on a lucky day, from Prescriptions for Universal Relief.

On lunar January fourth, twenty-seventh; February eighth, twentieth; March eighth, thirteenth; April second, sixteenth, nineteenth; May sixteenth, twentieth; June fourth, seventeenth, twenty-fourth; July third, fourth, twenty-eighth; August fifteenth, nineteenth, twentieth; September second, fourth, twenty-fifth; October seventh, twelfth, twenty second; November fifteenth, seventeenth, twentieth; December seventh, sixteenth, twentieth.

Plucking off the hair in the high noon by right hand and then smearing the place where hair plucked off with the natural juice of fresh ginger for three to five days, the black hair would grow, no white hair. This day one should not touch these things, including wine, sex, meat and parivyaya, the effect would like gods.[1]

The plucking off method of Taibai, when before the sun coming out, plucked off by a single girl will be perfect.

The lunar January fourth, twenty-seventh; February eighth, twentieth; March eighth, tenth, thirteenth; April third, sixteenth, nineteenth; May sixteenth, twentieth; June fourth, seventeenth, twenty-fourth; July second, fourth, eighteenth; August fifteenth, nineteenth, twentieth; September third, fourth, fifteenth; October seventh, twelfth, twenty-second; November fifteenth, seventeenth, twentieth; December seventh, sixteenth, twentieth.

Plucking off white hair with right hand, burying it in the shade. And then beating broken with ploughing iron no matter how much it is, boiling fresh ginger water with more than ten pieces of fructus caryophylli and five to seven pieces of cedar leaves. Soaking the inner side of chinaware into black, plucking off white hair, and then getting some as usage, using hand to smear then black hair will grow. As an experience, salt could be added in boiling fresh ginger water.[1]

\section{Gather of Medical Prescription Types recorded "medicine for hair dyeing"}

A strip of bone from the root of bidentate achyranthes, combined with marrow, using vertebra to open one end, with six to seven live leeches, one qian(old unit of measurement equals to 5 grams) of bluestone, half qian of Qinghai salt, a little sal ammoniac, all in powder shape and being put in the bone, then sealing the bone with paper. Until the leeches become water, using one qian of needle filing to mix well and then putting them in the bone then sealing the bone with oil paper. Hanging the bone in a clean place for seven days, or twenty-seven days better. When opening, the water becomes black, then use the inner part of the bone to wrap around fingers, dipping hair in the medicine to dye the hair, washing hair until all the medicine been absorbed by it. Drying the hair. Seven days later repeat the above steps. After three times of above, the color neither will fade nor burn forever. The must used book the same.

Plucking off white hair from the Biography of Juzong, the scholar lived in Huashan Mountain. All the men and women whose hair get white when they are young, should plucking off white hair facing the east in each the period of the day from 7 a.m. to 9 a.m. according to the method.

The lunar January fourth, twenty-seventh; February eighth, twentieth; March eighth, tenth; April third, sixteenth, eighteenth, nineteenth; May sixteenth, twentieth; June fourth, seventeenth, fourteenth, the must used book recorded fourteenth as twenty-fourth; July third, fourth, eighteenth; August fifteenth, nineteenth, twentieth; September third, fourth, fifteenth; October seventh, twelfth, twenty-second; November fifteenth, seventeenth, twentieth; December seventh, sixteenth, thirtieth.

The Compendium of Materia Medica recorded "horse tooth mirabilite":

Six qian of mirabilite, sixty percent of a bowl of water, until clean. Washing eyes according to the method for one year, eyes would be as clear as children. Lunar January third; February eighth; March fourth; April Fourth; May Fifth; June Fourth; July Third; August First; September thirteenth; October thirteenth; November sixteenth; December fifth.[3]

The Compendium of Materia Medica recorded "glaucoma washing method":

Once Song Zhongfu in Wusheng Jun(similar to county in Yuan Dynasty) had this disease for twenty years while eyes became clear as before by this method. Taking the newly picked green mulberry leaves and drying it in shade, burning it to keep its feature on a certain day of each month. Each time using one box of it to decoct in chinaware, reducing 20 percent of it and pour it out, 
clearing. Using this warm water to wash eyes, until hunred times, each time is effective. Lunar January eighth; February eighth; March Sixth; April Fourth; May Fifth; June Second; July Seventh; August Twentieth; September Twelfth; October Seventeenth; November Second; December Thirtieth. Prescriptions for Universal Relief.[3]

The Compendium of Materia Medica recorded "exotic prescription":

Using Cudrania tricuspidata Bur wood to boil soup and washing in warm water on a certain day, stop during the period of the day from $3 \mathrm{a} . \mathrm{m}$. to $5 \mathrm{a} . \mathrm{m}$.to the period of the day from $9 \mathrm{p}$. $\mathrm{m}$. to 11 p . m ., all efficient. No washing on these days: On the second day of Lunar January, February second, and March; April fifth, May fifteenth, June eleventh, the seventh day of July, second of August and September, nineteenth of October, November. December fourteenth. Prescription from Father Xu..[3]

Looking up the Chinese medical prescriptions, the date the Like Gods Prescription for Washing Hair and Treatment of Laucoma at Pathogenic Wind-toxic refered to may not be the date not suitable to use this medical prescription. The following is what recorded by "renewing white hair prescription" from "treasure prescription of Wei's family":

$\mathrm{Wu}$ radix angelicae, chrysanthemum, inula flower, cinnamon bark inner layer, white poria and sesamum indicum, each for three fen(unit of weight in ancient China, equals to 0.3 grams)

Piper cubeba, the root of bidentate achyranthes, each for 2(or 3)fen

Raspberry, Lotus beard dried in shade, each for 1 fen

Then be triturated as powder. Boiling it with wine and making it pill as big as seed of tung tree. When one has empty stomach, taking 39 pills with wine, further in the noon for 29 pills. When taking the pills one should either drink wine or have meal at the same time to prompt efficacy of the medicine. One day is enough to see the effect. White hair first becomes blue then gradually be black. This medicine can also cure all wind disease. If one wanted to test the medicine efficacy, he/she could use steamed cake to wrap the pill to feed dogs with white hair, then he/she would see it turns black at last. No radish, mutton and raw onion during the period of taking medicine.

If the date is: lunar January fourth, February sixth, March twelfth, April sixteenth, May twenty-first, June twenty-fourth, July twenty-first; August fifteenth, September sixteenth, October thirteenth, November fourth, December seventh, do not take the pill.

Compared with all the prescriptions above, the date the Like Gods Prescription for Washing Hair and Treatment of Laucoma at Pathogenic Wind-toxic refered to has no superposition, and the frequency of the date month by month is more than all the prescriptions above.

Holy peaceful be-nevolent prescriptions recorded:

People whose eyes light membrane covered with water has a quiet temper, can identify and see things clear, nothing can prevent his/her eyesight. For this, his/her mind relaxed and he/she can feel well, splenic organ would come to peace. Some visceral qi causes ailment and eyes go blind without ache or itch, the reason might be the liver and gall being hurt by wind-evil and poison gas inside body. The poison gas inside body undispersed gathers to eyes, the eyes then go blind.[2]

The poison gas inside body undispersed gathering to eyes causes glaucoma easily, so it can be concluded that the Like Gods Prescription for Washing Hair and Treatment of Laucoma at Pathogenic Wind-toxic is mainly used for treatment of glaucoma.

Inference based on date of washing eyes, compared with above prescriptions, the composition medicinal materials of the Like Gods Prescription for Washing Hair and Treatment of Laucoma at Pathogenic Wind-toxic may refer more to these two medicinal materials, one is nitre type, such as mirabilite, natrii sulfas etc. The Compendium of Materia Medica recorded:

It(pu mirabilite) disappears when in water, it can make all things digested, so we call it "xiao"(means disappearance,Chinese name of mirabilite). It was born in land of salt, similar to salt in its appearance. All cattle, horses skin are cooked by it, so today it has the name of salt mirabilite, skin mirabilite.

It was fried and refined into the basin, coagulated ones are under the basin, the rough ones are called pu mirabilite, the cutting edge ones are called mirabilite, while the ones with tooth are called horse tooth mirabilite. There are only pu mirabilite, mirabilite stone on Sheng Nong's herbal classic, then mirabilite appeared in Mingyi Bielu, the Compendium of Materia Medica in Jiayou Emperor of 
Song Dynasty, horse tooth mirabilite appeared. Today we call mirabilite and horse tooth mirabilite with the same name.[3]

The other is mulberry leaf, the Compendium of Materia Medica recorded:

Leaf, smell bitter, sweet, cold, with a little poison. Attending the fever, sweating, Detoxicating centipede venom. Taking fried and boiled leaves water, then one can get rid of dermatophytosis and edema, being good for the large intestine and small intestine. Fried and cooked, it can quench one's thirst in place of tea. Frying and then drinking is good for the five internal organs(heart, liver, spleen, lungs and kidneys), getting through joints as well as gas in body. Frying tender leaf with wine, all wind disease would be cured. Making it steamed(smashed), $\square \square$ yin wind ache sweating, and recovering the blood stasis, smoothing out with the fingers to a pulp and smear it on the wound by snake, worms[SIX]. Grinding into juice, incised wound and children kiss wound can be cured. Taking the fried soup of leaves, cholera, stomachache and emesis could be cured, boiled soup with dry leaves could also be useful for these conditions. Chicken mulberry leaves: boiled with water, and being taken when in cream shape, old rheumatism and garbage in the blood can be removed. Consumptive fever and cough can be cured. Improving eyesight and promoting hair growing.[4]

The efficacy of improving eyesight and promoting hair growing conforms more to the medical prescription name of the Like Gods Prescription for Washing Hair and Treatment of Laucoma at Pathogenic Wind-toxic.

\section{Textual criticisms and explanations on Medical Prescription}

The Medical Prescription is broken down piece sticking on the remaining text of tenth of the top of the Buddha Tathagata Mi Yin revised Yi all Bodhisattvas Wan Xing Shou Leng Yan Jing Volume, now it is included in the 282nd pages of Book Five of Khara-Khoto Documents Collected in Russia with serial number of A20V.

Medical Prescription has two rows with 15 words on each row. Regular script, black shade is uneven.

\section{(Missing)}

1. Knife-step medicine fragrant-flowered garlic cortex pruni Da Hui belongs to May Fifth, close

2. Diarrhea medicine long tail maggots mixed wine

(missing)

This medical prescription refers to two prescription names, they are knife-step medicine and diarrhea medicine. The former one is medicinal materials with composition, the later one is incomplete.

\section{Textual criticisms and explanations on "Knife-step Medicine"}

Key words related to "Knife-step Medicine" are "fragrant-flowered garlic", "cortex pruni", "Da Hui" and "May fifth". Looking up the Chinese medicine writings, no the appellation of " Knife-step Medicine" be found. Combined with the rest key words, similar medical prescriptions can be listed as follows:

1). Volume 320 of General Benevolentprescriptions recorded "all kinds of grass powder, one for emergency, Bai ling cream, Big effect prescription":

Let four people go to four directions and each one picks root and leaves of grass of one fang within five li (500 meters) in the early morning of May Fifth. No missing. In the high noon to cut finely. Smashing with Dui(a kind of hammer) and making it thoroughly cooked combined with lime. One Dan(equals to 150 Jin, jin, a unit of weight (=1/2 kilogram) ) grass with one Dan lime. Firstly chiseling the mulberry in Dashi to make it be able to take medicine. Taking medicine out of the inner hole. Making it stable and covering it with mulberry bark. Using sesame oil to smash the lime, mud sticked to it to make it tight without gas leaking. Again using mulberry bark to twine to make it tight. Taking it out till September ninth and drying in shade. For about one hundred days, the medicine forms. Smashing the medicine, and drying it in the sun. Smashing again. Then laying sik sieve aside. All incised wound with blood can be cured by medicine covered then. Don't move. Then one would be recovered in less than ten days. 
2). The 187th volume of Gather of Medical Prescriptions Types recorded that "treat incised wound, stop blood, eliminate pains, get rid of wind, join muscles and bones, generate muscles, way of refined lime powder prescription"[4]

Eliminate the skin of apricot nutlet and smash it into mud shape equal amount of lime

Then boil medicines, the same grinding two or three times of lard and Fuzhi in daytime, then recovered.

Then on dragon boat day, taking one Jin of Baicao head, shallot of five Jin or fragrant-flowered garlic better and washing them. Smashing it in stone mortar finely, mixed with ore lime and be made into pill, it would be used as Knife-wound medicine.

3). "Overview of towel gourd" in the twenty-eighth volume of Greens in the Compendium of Materia Medica recorded "Knife-wound god medicine"[3]

Old lime, new lime, roots and leaves of towel gourd(two leaves when first seeding), leek root, each with the equal amount. Smashing all above for one thousand times to make it into a cake. Drying in shade in powder shape. Wiping. It can stop blood as well as make pain stable and make muscles grow, like god effects.

4). The third volume of Xiangzu Notes recorded "Yepu State South Cliff spreads prescriptions for treatment of knife-wound"[5]

On dragon boat day, taking fragrant-flowered garlic and smashing it into juice. Cooked as cake with lime mixed. Using it to cover the wound, blood would stop. Even the bone was damaged, would be recovered by this, wonderful effect.

The twenty-first volume of Continued Famous Doctors Class Case recorded: [6]

On dragon boat day, taking fragrant-flowered garlic and smashing it into juice. Cooked as cake with forging stone mixed and smashed, drying in shade. Using it for treatment of all wounds by covering it onto the wound. Even the bone was damaged, would be recovered by this, wonderful effect.

Based on the above prescriptions, "knife medicine" Textual criticisms and explanations can be implemented.

a). "Knife-step medicine" may be "Knife-wound medicine".

b). "Leek" refers to fragrant-flowered garlic(smashed into juice). According to the record of the Compendium of Materia Medica: "Leek" has the effect of "make people eat, stop diarrhea, blood and pus[2], therefore, "Leek" is the main composition medicinal materials in this prescription.

c). "Da Hui" should refer to the medical materials formed by burning "leeks" with "lime". As recorded in the Compendium of Materia Medica, lime has: the function of "eliminating blood and stabling the pain"; record of General Benevolentprescriptions: "Da Hui" is "lime calcining straw knots willow tree strip cut into pieces two Liang five Qian"[7] In the prescription, "Da Hui" has the function of "calcining" and "eliminating blood and making pain stable".

d). The "Cortex Pruni" plays a role of "binding"(similar to "gauze" in

Nowadays). Looking up the Chinese Medical works, cortex pruni did not have the function of treatment of knife wound or stopping blood. As recorded in Men and Women Special Effects Good Prescription, cortex pruni has "relief taking bitter almond poison method": "frying cortex pruni with water and then drinking, it will be recovered. One can also be saved even he/she is going to die."[8] While as recorded by the Compendium of Materia Medica, Apricot kernels has the function of hemostasis: Apricot kernels no blood stopping by all medicine, while immediately the blood would be stopped when taking this. Use the sweet almond, combined with clausena lansium, burning as powder. Each time taking three Qian. Taking it with wine when heart is empty." On the basis of inference, the function of "cortex pruni" may be similar with "mulberry bark".

e). "May fifth •Close" means "using this prescription on May fifth then the disease would be recovered(totally)."

\section{(Two) The textual criticisms and explanations on "diarrhea medicine"}

The "diarrhea medicine" of Medical Prescription has prescription name, while different from "Knife-step Medicine", the composition medicinal materials are incomplete with only one medical material related, that is "the long tail maggots", besides the medicine taking method "with wine". Looking up Chinese medical works, there was the name of "diarrhea medicine" while no explain of composition medicinal materials.

The Compendium of Materia Medica recorded the "diarrhea medicine" as follows: 
Taking (The Magnolia bark skin) with diarrhea medicine, then the intestines and stomach would be full.

It can be speculated that main effect of "diarrhea medicine" recorded in Medical Prescription should be related to treatment of the type of "intestinal tract disease".

The efficacy, production and use of "the long tail maggots", composition medicinal materials mentioned by "diarrhea medicine" recorded in Medical Prescription are as follows:

"Treatment of Laucoma" is recorded in the eleventh volume of Supplement to Invaluable Prescriptions for Ready Reference:

Clean the long tail maggots and dry them in the sun, then mash them into powder. Put it in the eyes, disease would be recovered.[9]

"Treatment of Laucoma"in the sixty-fifth volume of Gather of Medical Prescription Types:

Clean the long tail maggots and dry them in the sun, then mash them into powder. Put it in the eyes, disease would be recovered.[4]

It can be concluded that "long tail maggots" mainly treat eye disease. The relationship between "eye disease" and "diarrhea" can be found in the record of General Benevolentprescriptions:

Though the name of Xie and Li are different, the feelings are the same, stomach is a place full of rice and water. It mainly provides essence to support the five internal organs, while the bad part be transferred to large intestine. Ge's said. For the reason of inner cold, the food makes it blocked. For the outside reason of hurt by fever of cold, diarrhea forms.

With long-time diarrhea, one would feel cold. Full of swell. The Xia Jiao is relatively colder while the Shang Jiao hotter. Fumigation in liver, then eyes faint and slight corneal opacity appears.

In the inference based on, the recorded "diarrhea medicine" in Medical Prescription may be related to "eye disease".

In conclusion, the two prescriptions collected in Khara-Khoto Documents Collected in Russia belong to hand-copied version in Yuan Dynasty, it can be concluded that both may originate from some medical works of somebody unknown after St. Ji ZongLu in Yuan Dynasty, and both can be joined together; both of them can be showed in medical works in Tang and Song Dynasty, such as Supplement to Invaluable Prescriptions for Ready Reference, Holy peaceful be-nevolent prescriptions, General benevolentprescriptions, Exotic prescription, and most be influenced by medicals in Tang and Song Dynasty and still be remained and used in Yuan Dynasty. This has significance on the compiling and edition scattering and emendation of ancient Chinese medical works and besides it will promote the development of Chinese medical history research.

\section{Acknowledgments}

This paper is for the 2013 youth fund projects of the ministry of education humanities and social science, the project name is Local Folk Culture and the Modern Significance Research of Western Region-taking Heritage of Jianghuai, Tam County, Gansu Province for Example, serial number:( 13YJCZH104).

\section{References}

[1] (Ming Dynasty)Jin Li Meng etc., compiled. Zhejiang institute of traditional Chinese medicine, Hunan Chinese medicine hospital, proofreading: eighty-three volume of Gather of medical prescriptions, Hair type. Second, People's medical publishing house, 1981.

[2] (Song Dynasty) Wang Huaiyin etc., compiled: the thirty-third volume of Holy Peaceful Be-nevolent Prescriptions, People's medical publishing house, 1958

[3] (Ming Dynasty)Li Shi Zhen: the Compendium of Materia Medica, People's medical publishing house, 1975

[4] Sheng Zeng Xiu etc. Compiled: Gather of Medical Prescription Types, People's medical publishing house, 2006 
[5] (Qing Dynasty)Wang Shizhen: the third volume of Xiangzu Notes, Shanghai Chinese Classics Publishing House, 1982.

[6] (Qing Dynasty) Qian Tang Wei Zhi Xiu compiled Bin Shao Heng recalibrated: the twenty-first volume of Continued Famous Doctors Class Case, Tumbled, People's medical publishing house, 1982.

[7] (Ming Dynasty) Zhu Su, etc.,: the forty-ninth volume of General Benevolentprescriptions, the first. Overview of Eyebrow and beard, Taiwan commercial press, 1983.

[8] Unknown: the fifth volume of Men and Women Special Effects Good Prescription, relieving suicide type, 1934 compiled.

[9] (Tang Dynasty) Sun Si Miao: the eleventh volume Childre of Supplement to Invaluable Prescriptions for Ready Reference, People's medical publishing house, 1982. 